\title{
Child Relation
}

National Cancer Institute

\section{Source}

National Cancer Institute. Child Relation. NCI Thesaurus. Code C150886.

An individual's biological or non-biological first generation offspring, including but not

limited to biological children (including those born outside of marriage), adopted children, step children, and foster children. 